Check for updates

Cite this: Chem. Sci., 2017, 8, 7998

Received 17th August 2017

Accepted 2nd October 2017

DOI: $10.1039 / \mathrm{c} 7 \mathrm{sc} 03612 \mathrm{~d}$

rsc.li/chemical-science

\section{A practical and scalable system for heteroaryl amino acid synthesis $\uparrow$}

\author{
R. A. Aycock, D. B. Vogt and N. T. Jui (D)*
}

A robust system for the preparation of $\beta$-heteroaryl $\alpha$-amino acid derivatives has been developed using photoredox catalysis. This system operates via regiospecific activation of halogenated pyridines (or other heterocycles) and conjugate addition to dehydroalanine derivatives to deliver a wide range of unnatural amino acids. This process was conducted with good efficiency on large scale, the application of these conditions to amino ketone synthesis is shown, and a simple protocol is given for the preparation of enantioenriched amino acid synthesis, from a number of radical precursors.

\section{Introduction}

Amino acids play a central role in the chemical and biological sciences. As primary members of the chiral pool, they are precursors to drugs, ${ }^{1}$ chiral auxiliaries, ${ }^{2}$ and catalysts. ${ }^{3}$ In addition, they are fundamental building blocks for the construction of biomolecules. The use of peptides as therapeutic agents is attractive because they can display extremely diverse, potent, and selective biological activities. ${ }^{4}$ However, there are significant challenges in peptide drug design, including low metabolic stability or poor physical properties. One proven strategy for overcoming these challenges involves substitution of the native residues with unnatural amino acids (synthetic mutagenesis). ${ }^{5}$ Nitrogen-containing heteroaromatics are common in pharmaceuticals because they directly alter the solubility, metabolic stability, and binding affinity of the molecules that they comprise. ${ }^{6}$ As such, heteroarene-containing unnatural amino acids are promising tools in the design of peptide therapeutics.

Pyridine incorporation has a dramatic impact on the properties of amino acids and peptides. For example, azatyrosinea natural product that differs from the essential amino acid tyrosine by substitution of a single atom-displays potent antibiotic and antitumor properties (Fig. 1A). ${ }^{7}$ Installation of the 3-pyridylalanine (3-pyr-Ala) residue in the gonadotropinreleasing hormone antagonist cetrorelix (Fig. 1B) was found to improve both aqueous solubility and receptor affinity, ${ }^{8}$ and similar effects were observed in the development of other peptide hormones (not shown). ${ }^{5 b-\boldsymbol{d}}$ As part of a program centered on the catalytic functionalization of heteroaromatics, we target the development of impactful synthetic methods for

Department of Chemistry and Winship Cancer Institute, Emory University, Atlanta, GA 30322, USA. E-mail: njui@emory.edu

$\dagger$ Electronic supplementary information (ESI) available. See DOI: $10.1039 / \mathrm{c} 7 \mathrm{sc} 03612 \mathrm{~d}$ the construction of novel $\beta$-heteroaryl $\alpha$-amino acids through a radical conjugate addition mechanism.

We have found that pyridyl halide activation via single electron reduction using photoredox catalysts ${ }^{9}$ can be accomplished, and that the intermolecular reactivity of the resulting radical species can be dictated by the reaction conditions. ${ }^{10,11}$ More specifically, we found that pyridyl radicals display nucleophilic reactivity in aqueous DMSO, and they readily couple with electron-poor alkenes. We questioned whether this approach could be translated to heteroaryl amino acid synthesis through radical conjugate addition to dehydroalanine derivatives. There are a number of powerful methods for the synthesis

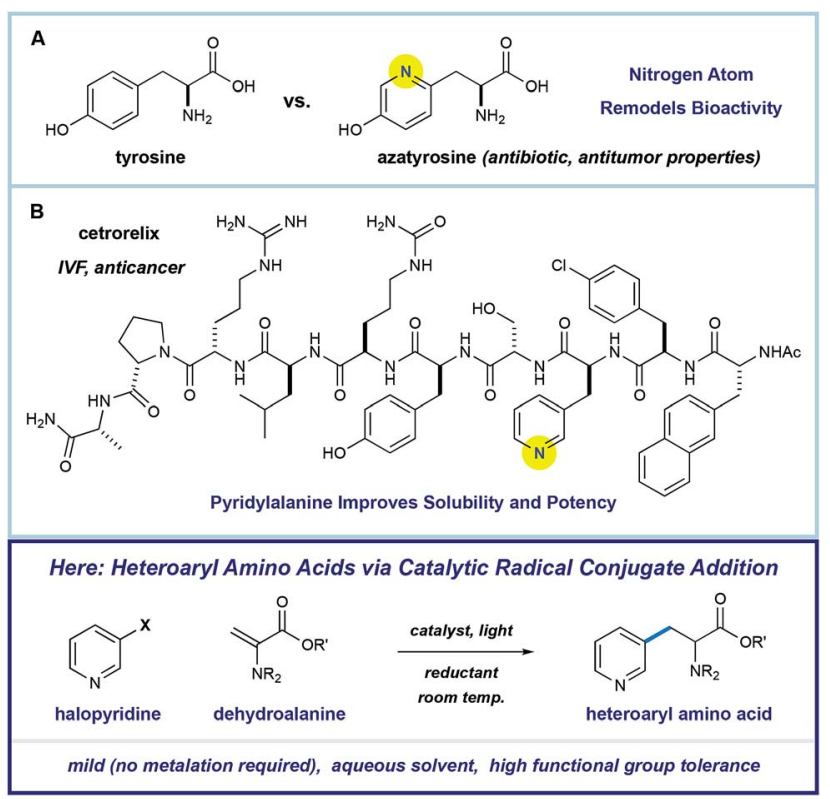

Fig. 1 Impact of pyridine incorporation into amino acids and peptide drugs. 
of unnatural $\beta$-heteroaryl $\alpha$-amino acids, including malonate (or enolate) alkylation, ${ }^{12}$ cross-coupling of serine-derived organometallic reagents, ${ }^{13}$ and reduction of dehydroamino acid derivatives. ${ }^{14}$ However, strategies based on radical addition to DHA derivatives are unique due to the highly-chemoselective nature of radical species, and the broad functional group tolerance that results. ${ }^{15}$ Alkyl radical addition to DHA has been effectively accomplished even in the complex setting of intact proteins.$^{16}$ While this is a highly attractive attribute, a radical approach to heteroaryl amino acids is currently unknown. Here, we describe the successful translation of our reductive heteroarene activation system to amino acid synthesis.

\section{Results and discussion}

Shown in Fig. 2 is a mechanistic picture that is consistent with our observations. Excitation of the photocatalyst $\left[\operatorname{Ir}(\mathrm{ppy})_{2}\right.$ (dtbbpy) $] \mathrm{PF}_{6}\left([\mathrm{Ir}]^{1+}\right)$, followed by reductive quenching of the excited state by Hantzsch ester (HEH) gives rise to the $[\mathrm{Ir}]^{0}$ $\left(E_{1 / 2}=-1.51 \mathrm{~V}\right) .{ }^{17}$ Stern-Volmer quenching studies indicated that Hantzsch ester is the most significant excited state quencher (see ESI for details $\dagger$ ). Single electron reduction of halo pyridine $\mathbf{I}$, followed by rapid mesolytic cleavage in polar solvents $(\mathrm{X}=\mathrm{Br}, \mathrm{I})^{18}$ affords heteroaryl radical intermediate II, which exhibits nucleophilic radical behavior in aqueous DMSO. ${ }^{10 a}$ It is possible that halopyridine reduction is assisted by protonation, as each catalytic turnover produces an nominal equivalent of Hantzsch pyridinium bromide $\left(\mathrm{HEH}^{+} \mathrm{Br}^{-}\right)$. Hydrodehalogenation $(\mathrm{HDH})$ of the arene is observed as a common
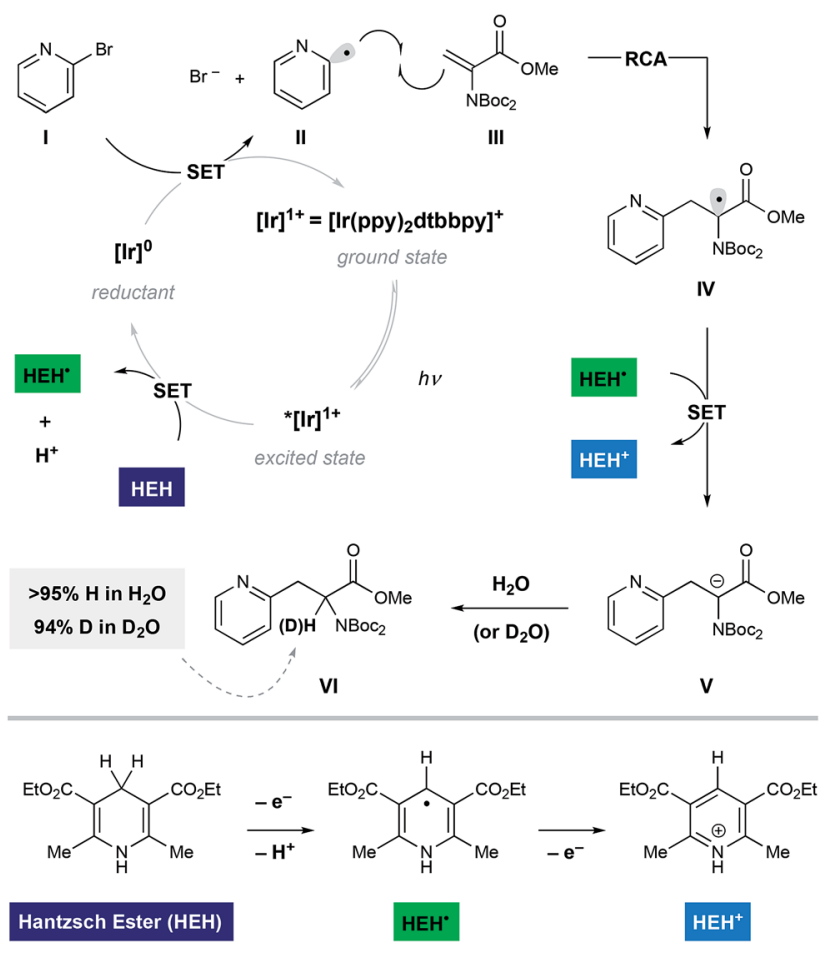

Fig. 2 A proposed mechanism of heteroaryl radical conjugate addition to dehydroalanine. byproduct, but this undesired pathway can be suppressed by limiting the solubility of the stoichiometric reductant, Hantzsch ester (HEH), in accord with our previous findings. Radical conjugate addition (RCA) to dehydroalanine III and subsequent single electron reduction of the nascent radical IV would deliver the corresponding enolate $\mathbf{V}$. The intermediacy of $\mathbf{V}$ is supported by the fact that the $\alpha-\mathrm{H}$ amino acid product VI is produced in the presence of $\mathrm{H}_{2} \mathrm{O}$ as a cosolvent (regardless of $\mathrm{H} / \mathrm{D}$ labeling of $\mathrm{HEH}$ ). Conversely, when $\mathrm{D}_{2} \mathrm{O}$ is used as a cosolvent, complete deuterium incorporation is obtained at the $\alpha$-position.

As illustrated in Table 1, we identified conditions that efficiently unite 2-bromo-5-hydroxypyridine with the indicated dehydroalanine derivative (readily accessed on $35 \mathrm{~g}$ scale from Boc-Ser-OMe) to give the protected azatyrosine 1 in $98 \%$ NMR yield (entry 1). These conditions employ $1 \mathrm{~mol} \%$ of the photosensitizer $\left[\operatorname{Ir}(\mathrm{ppy})_{2}(\mathrm{dtbbpy})\right] \mathrm{PF}_{6}$ (excited by irradiation with a commercial blue LED) and Hantzsch ester (1.5 equiv.) as a stoichiometric reductant in aqueous DMSO. Control experiments indicated that all of these components are necessary for the reaction (entries $2-4,0 \%$ yield), and that use of the prototypical $\mathrm{Ru}(\mathrm{bpy})_{3}{ }^{2+}$ chromophore results in product formation, although with diminished efficiency (entry 5, 58\% yield). Omission of water as a cosolvent was not well tolerated here (entry $6,14 \%$ yield), a finding that is in consistent with our previous observations. ${ }^{10 a}$ We found that other aqueous solvent mixtures can be used (entries 7 and $8,35 \%$ and $71 \%$ yield, respectively), and that this photoredox system is remarkably robust; an experiment using bourbon as solvent (open to air) afforded the desired product in 93\% yield (entry 9). Importantly, protection of the phenol O-H function was not required under these mild radical conditions.

Using the optimized protocol outlined above, we found that the heteroaryl halide scope of this transformation is broad (as

Table 1 Optimal conditions for pyridyl radical addition to a dehydroalanine substrate ${ }^{a}$

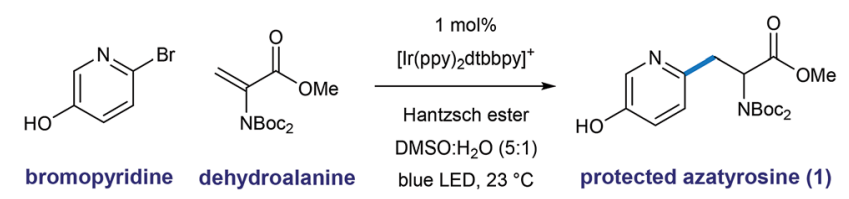

\begin{tabular}{lll}
\hline Entry & Deviation from optimal conditions & Yield of $1^{b}$ \\
\hline 1 & None & $98 \%$ \\
2 & Without Hantzsch ester & $0 \%$ \\
3 & Without light & $0 \%$ \\
4 & Without catalyst & $0 \%$ \\
5 & $\mathrm{Ru}\left(\right.$ bpy) ${ }_{3} \mathrm{Cl}_{2}$ as catalyst & $58 \%$ \\
6 & Without $\mathrm{H}_{2} \mathrm{O}$ & $14 \%$ \\
7 & DMF $: \mathrm{H}_{2} \mathrm{O}(5: 1)$ as solvent & $35 \%$ \\
8 & EtOH $: \mathrm{H}_{2} \mathrm{O}(5: 1)$ as solvent & $71 \%$ \\
9 & Bourbon as solvent (open to air) & $93 \%$
\end{tabular}

${ }^{a}$ Conditions: 2-bromo-5-hydroxypyridine $(0.2 \mathrm{mmol})$, dehydroalanine (0.4 mmol), $\operatorname{Ir}(\mathrm{ppy})_{2} \mathrm{dtbbpy} \cdot \mathrm{PF}_{6}(1 \mathrm{~mol} \%)$, Hantzsch ester $(0.3 \mathrm{mmol})$, $\mathrm{H}_{2} \mathrm{O}(0.33 \mathrm{~mL})$, DMSO $(1.66 \mathrm{~mL})$, blue LED, $23{ }^{\circ} \mathrm{C}, 16 \mathrm{~h} .{ }^{b}$ Yield determined by NMR. 
shown in Table 2). Some reactions are complete in as little as 2 hours, but each experiment was conducted overnight (16 h) for consistency and convenience without negatively impacting the yields. Regiospecific activation of each pyridyl position is possible via single electron reduction, and these conditions effectively delivered amino ester products from 2- and 3-iodopyridine (2 and 10), in 97\% and $73 \%$ yield, respectively. Although less efficient, 4-iodopyridine also affords 4-pyridylalanine in useful yield $(\mathbf{1 6}, 34 \%$ yield), where reductive pyridine production is a significant alternative pathway. Methyl substitution is well-tolerated at all positions of 2-bromo pyridines, cleanly furnishing the corresponding pyridylalanines 3-6 in very high yield (93-97\% yield). Reaction of 2-bromo-5trifluoromethylpyridine (7) efficiently afforded product in $94 \%$ yield. Electron-donating groups are well-tolerated including amino (9, 71\% yield), phenol (11, 67\% yield), amide (12, 73\% yield), and methoxy (17, 66\% yield) groups. Dihalogenated pyridines can be programmed for regiospecific radical formation and subsequent conjugate addition at any position, preserving 2-chloro-substituents in the presence of more reactive iodo-substituents. Coupling reactions of 2-chloro-3iodo- (14), 2-chloro-4-iodo-(18), 2-chloro-5-iodo-(13), and 2chloro-3-methyl-4-iodopyridine (19) each gave single pyridylalanine products in good yield (73-83\% yield). 2,5-Diiodopyridine is selectively activated at the more electrophilic 2position to afford the corresponding amino ester (8) as a single regioisomer in $74 \%$ yield. We found that halopyrimidines are also viable substrates in this process: 4-iodo-2-(methylthio) pyrimidine (15) and 4-bromodeazapurine (21) gave product in $80 \%$ and $95 \%$ yield respectively. This photoredox process is amenable to gram-scale preparation of heteroaryl amino acid synthesis, without the need for special equipment. We reacted $25 \mathrm{mmol}$ of 2-bromopyridine with a slight excess (1.2 equivalents, $30 \mathrm{mmol}$ ) of the dehydroalanine substrate. In the presence of 1.0 equivalent of Hantzsch ester, in the presence of 1.0 equivalent of Hantzsch ester, and only $0.1 \mathrm{~mol} \%$ (23 $\mathrm{mg}$ ) of the iridium photoredox catalyst, the desired pyridylalanine derivative 2 was produced in $84 \%$ yield $(8.0 \mathrm{~g})$ after purification. As anticipated, selective unveiling of the amine and acid groups (in compound 2) using standard conditions went without issue.

Table 2 Catalytic amino acid synthesis: scope of the halogenated heteroarene ${ }^{a}$
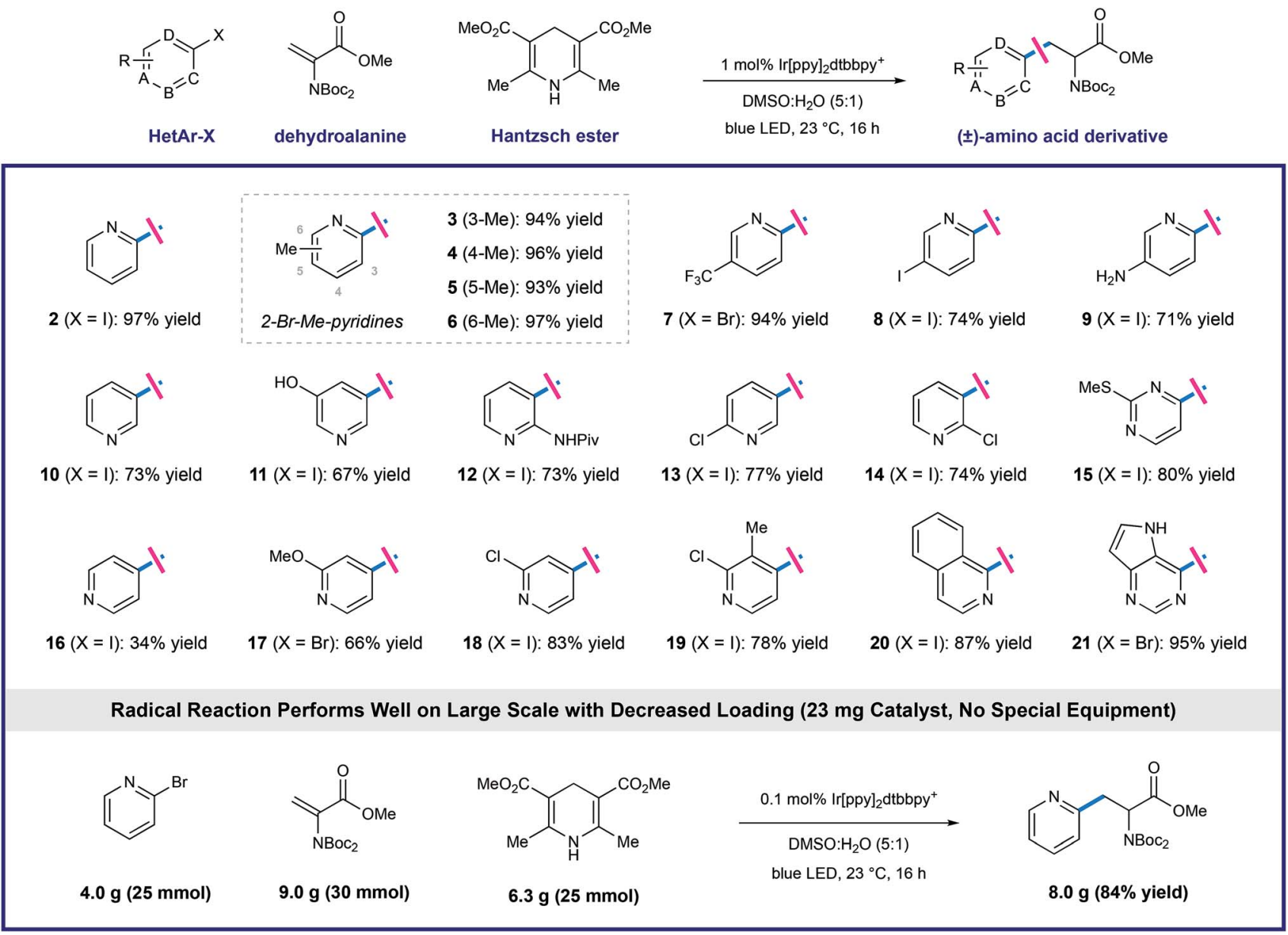

${ }^{a}$ Conditions: halogenated heteroarene $(1.0 \mathrm{mmol})$, dehydroalanine $(2.0 \mathrm{mmol}), \operatorname{Ir}(\mathrm{ppy})_{2} \mathrm{dtbbpy} \cdot \mathrm{PF}_{6}(1.0 \mathrm{~mol} \%), \mathrm{Hantzsch}$ ester $(\mathrm{HEH}, 1.3-1.5$ $\mathrm{mmol}), \mathrm{H}_{2} \mathrm{O}(1.7 \mathrm{~mL})$, DMSO $(8.3 \mathrm{~mL})$, blue LED, $23{ }^{\circ} \mathrm{C}, 16 \mathrm{~h}$, isolated yields shown. 
Hydrolysis of the methyl ester (2.0 equiv. of $\mathrm{LiOH}$ in $\mathrm{THF} / \mathrm{H}_{2} \mathrm{O}$ ) occurred with preservation of both Boc groups. Exposure of 2 to trifluoroacetic acid in $\mathrm{CH}_{2} \mathrm{Cl}_{2}$ revealed the free amine as the TFA salt while leaving the methyl ester intact. Finally, sequential treatment of 2 with $\mathrm{KOH}$ in $\mathrm{EtOH} / \mathrm{H}_{2} \mathrm{O}$ followed by direct acidification of the reaction mixture with $\mathrm{HCl}$ afforded the fully deprotected 2-pyridylalanine as the double $\mathrm{HCl}$ salt. Each of these processes occurred in high yield at room temperature (see ESI for details $\dagger$ ).

We conducted a brief evaluation of the scope of aminosubstituted alkenes with the expectation that this reaction template could be flexibly utilized to deliver other amino acid or amino-carbonyl substructures. We found that dehydroamino acid substrates with methyl- and phenyl-substituents in the $\beta$ position could be successfully employed, giving rise to products 22 and 23 in acceptable yield (66\% and 54\% yield, respectively) with modest diastereocontrol. Replacement of the $\alpha$-imide group in the alkene starting material (a structural artifact of dehydroalanine synthesis via $\mathrm{Boc}_{2} \mathrm{O}$-induced $\beta$-elimination) with an $\mathrm{N}-\mathrm{H}$ aniline group or electronically diverse arylmethylamine groups was tolerated, although diastereoselectivity was low (25-28, 66-75\% yield, $\leq 3: 1 \mathrm{dr}$ ). These radical conjugate addition conditions directly translated to the synthesis of $\beta$-heteroaryl $\alpha$-amino ketone derivatives 29-31, giving the desired products in $64-77 \%$ yield. These results are notable because they show the ability of this mild radical system to accomplish the formation of other of $\alpha$-aminocarbonyl classes.

We have demonstrated that this process is robust, scalable, and generally applicable for the synthesis of many heteroaryl

Table 3 Radical conjugate addition: scope of the amino-substituted alkene coupling partner ${ }^{a}$

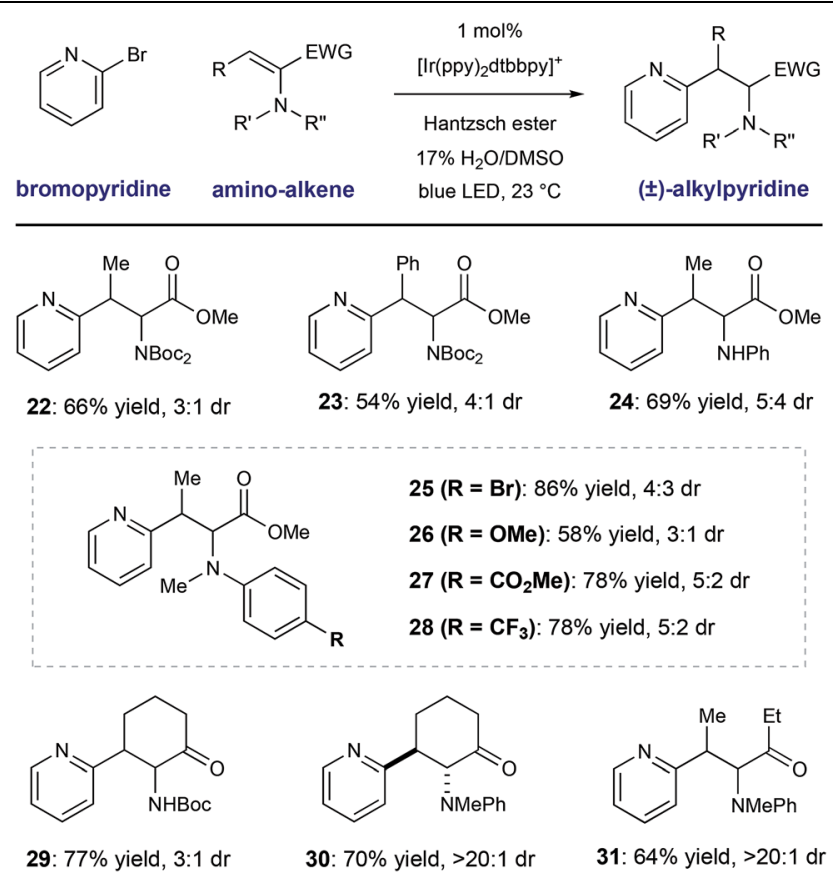

${ }^{a}$ Conditions as in Table 2, diastereomeric ratio (dr) determined by ${ }^{1} \mathrm{H}$ NMR. amino acid and ketone derivatives. However, we recognize that the formation of products as racemic mixtures represents a main limitation of this method. To address this, we prepared the chiral tert-butyl oxazolidinone 32 that was described by Beckwith, ${ }^{19}$ building on early work by Karady, ${ }^{20}$ and Seebach. ${ }^{21}$ In accord with early studies, we found that heteroaryl radical addition followed by diastereoselective protonation from the less hindered $R e$-face could be achieved with a variety of haloheteroarenes, furnished syn-products 33-36 with complete diasterocontrol (57-80\% yield, >20 : $1 \mathrm{dr}$ ). Concurrent carbamate cleavage and hemiaminal hydrolysis of 36 under acidic conditions cleanly afforded the amino acid 37 with retention of stereochemical purity (98\% yield, 97\% ee) (Table 3 ).

Other reducible radical precursors can be employed without modification of the reaction conditions to afford oxazolidinone adducts as single diastereomers. For example, the reaction of

Table 4 Diastereoselective RCA to Karady-Beckwith Alkene ${ }^{a}$
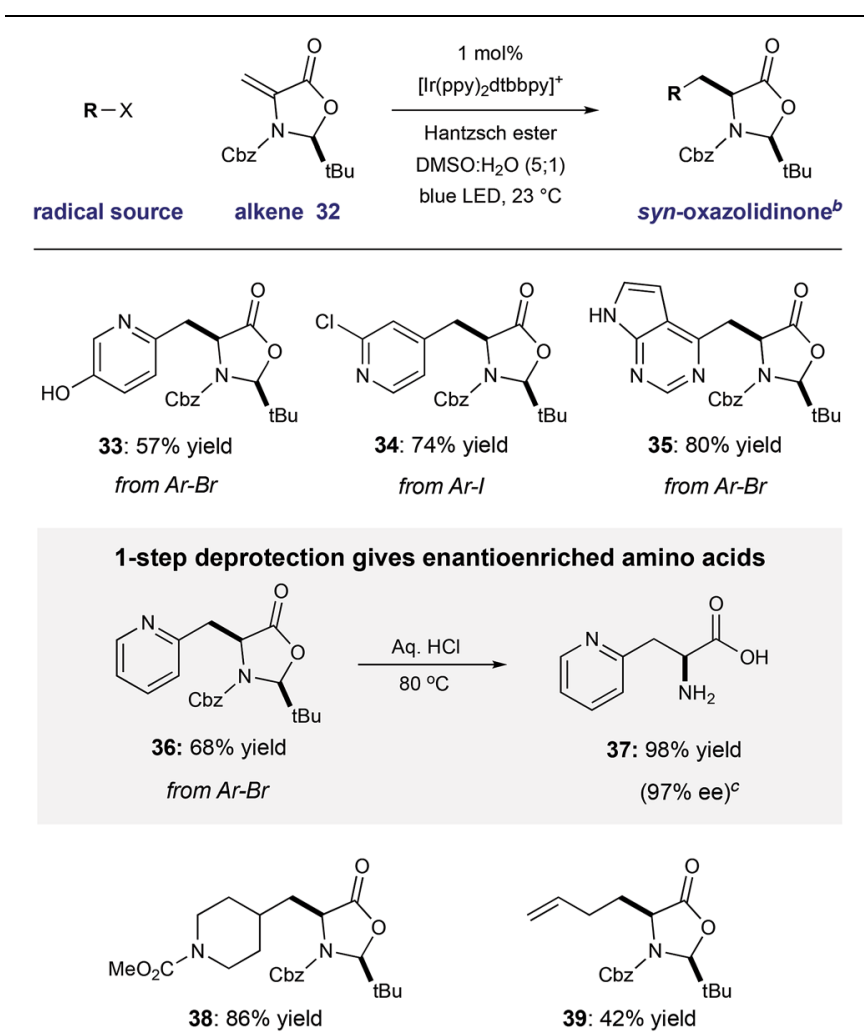
from NHPI ester from allyl bromide<smiles>O=C1OC(Cc2ccccc2)N(C(=O)OC(F)(F)F)C1CC(F)(F)F</smiles>

40: $63 \%$ yield ${ }^{d}$ from $\mathrm{F}_{3} \mathrm{C}-\mathrm{I}$<smiles>CCOC(=O)C(F)(F)CC1C(=O)OC(C(=O)c2ccccc2)N1Cc1ccccc1</smiles>

41: $93 \%$ yield

from alkyl bromide<smiles>NC(=O)C(F)(F)CC1C(=O)OC(C(=O)c2ccccc2)N1C(=O)c1ccccc1</smiles>

42: $60 \%$ yield

from alkyl bromide
${ }^{a}$ Conditions: halogenated heteroarene (1.0 equiv.), dehydroalanine (2.0 equiv.), $\operatorname{Ir}(\mathrm{ppy})_{2} \mathrm{dtbbpy} \cdot \mathrm{PF}_{6}(1.0 \mathrm{~mol} \%)$, Hantzsch ester ( $\mathrm{HEH}, 1.3$ equiv.), DMSO $/ \mathrm{H}_{2} \mathrm{O}(5: 1,0.1 \mathrm{M})$, blue LED, $23{ }^{\circ} \mathrm{C}, 16 \mathrm{~h}$, isolated yields shown. ${ }^{b}$ The syn isomer was observed with $>20: 1$ selectivity in all cases. ${ }^{c}$ Enantiomeric excess (\% ee) determined by chiral HPLC.

${ }^{d}$ Alkene 32 used as limiting reagent. 
allyl bromide gives oxazolidinone 39 (42\% yield). A redox-active $N$-hydroxyphthalimide ester ${ }^{22}$ reacted to give 39 in high yield (86\% yield). Finally, reducible fluorinated alky halides operate within this manifold, affording oxazolidinone adducts 40-42 with good efficiency (60-93\% yield). Deprotection of two of these products would directly yield fluorinated amino acids which have been enabling tools in a number of biomedical applications. ${ }^{23}$ For example, the difluorinated phosphonate $\mathrm{L}^{-}$ pSer minic (deprotected 41) is an important tool in the study of kinase-dependent signal transduction. ${ }^{23 a}$ Because chiral alkene 32 is easily accessible from cysteine (detailed in the ESI $\dagger$ ), and both enantiomers of this starting material are commercial, this strategy would enable access to either enantiomer of the unnatural heteroaryl amino acids (Table 4).

\section{Conclusions}

In summary, we have described an efficient catalytic system for the preparation of unnatural $\alpha$-amino acids. This protocol is effective for regiospecific generation of a broad range of heteroaryl radicals, and intermolecular coupling with dehydroamino acid derivatives and $\alpha$-aminoenones. We demonstrate that this photoredox system can be conducted on large scale using nearstoichiometric conditions with good efficiency. We also show that diastereoselective radical conjugate addition to a chiral alkene is a viable strategy to access enantioenriched products, and that this process allows utilization of a range of radical precursors. The application of these findings to the synthesis of other valuable, highly complex products is a current aim of our program.

\section{Conflicts of interest}

There are no conflicts to declare.

\section{Acknowledgements}

Financial support was provided by Emory University and Winship Cancer Institute. We thank Prof. S. Blakey and Prof. R. B. Dyer for generous use of instrumentation, as well as Brooke Andrews for helpful discussions and experimental assistance.

\section{Notes and references}

1 (a) C. F. Deacon, Diabetes, Obes. Metab., 2011, 13, 7-18; (b) Y. S. Tsantrizos, Acc. Chem. Res., 2008, 41, 1252-1263.

2 (a) D. A. Evans, G. Helmchen and M. Reuping, in Asymmetric Synthesis: The Essentials, 2007, pp. 3-9; (b) Y. Gnas and F. Glorius, Synthesis, 2006, 12, 1899-1930.

3 (a) A. G. Doyle and E. N. Jacobsen, Chem. Rev., 2007, 107, 5713-5743; (b) E. A. C. Davie, S. M. Mennen, Y. Xu and S. J. Miller, Chem. Rev., 2007, 107, 5759-5812; (c) E. J. Corey and C. J. Helal, Angew. Chem., Int. Ed. Engl., 1998, 37, 1986-2012; (d) G. Helmchen and A. Pfaltz, Acc. Chem. Res., 2000, 33, 336-345; (e) F.-L. Zhang, K. Hong, T.-J. Li, H. Park and J.-Q. Yu, Science, 2016, 351, 252-256; $(f)$ D. W. C. MacMillan, Nature, 2008, 455, 304-308; $(g)$
K. Sakthivel, W. Notz, T. Bui and C. F. Barbas, J. Am. Chem. Soc., 2001, 123, 5260-5267; (h) S. Bertelsen and K. A. Jørgensen, Chem. Soc. Rev., 2009, 38, 2178-2189.

4 (a) A. A. Kaspar and J. M. Reichert, Drug Discovery Today, 2013, 18, 807-817; (b) K. Fosgerau and T. Hoffmann, Drug Discovery Today, 2015, 20, 122-128.

5 (a) M. A. T. Blaskovich, J. Med. Chem., 2016, 59, 10807-10836. For examples in synthetic peptide hormones, see: $(b)$ T. Reissmann, A. V. Schally, P. Bouchard, H. Riethmuller and J. Engel, Hum. Reprod. Update, 2000, 6, 322-331; (c) K. Folkers, C. Y. Bowers, T. Kubiak and J. Stepinski, Biochem. Biophys. Res. Commun., 1983, 111, 1089-1095; (d) T. Asami, N. Nishizawa, H. Matsui, K. Nishibori, Y. Ishibashi, Y. Horikoshi, M. Nakayama, S. I. Matsumoto, N. Tarui, M. Yamaguchi, H. Matsumoto, T. Ohtaki and C. Kitada, J. Med. Chem., 2013, 56, 8298-8307.

6 (a) E. Vitaku, D. T. Smith and J. T. Njardarson, J. Med. Chem., 2014, 57, 10257-10274; (b) T. J. Ritchie, S. J. F. Macdonald, S. Peace, S. D. Pickett and C. N. Luscombe, Med. Chem. Commun., 2012, 3, 1062.

7 (a) S. Inouye, T. Shomura, T. Tsuruoka, Y. Ogawa, H. Watanabe, J. Yoshida and T. Niida, Chem. Pharm. Bull., 1975, 23, 2669-2677; (b) M. Izawa, S. Takayama, N. ShindoOkada, S. Doi, M. Kimura, M. Katsuki and S. Nishimura, Cancer Res., 1992, 52, 1628-1630.

8 T. Beckers, M. Bernd, B. Kutscher, R. Kühne, S. Hoffmann and T. Reissmann, Biochem. Biophys. Res. Commun., 2001, 289, 653-663.

9 (a) N. A. Romero and D. A. Nicewicz, Chem. Rev., 2016, 116, 10075-10166; (b) C. K. Prier, D. A. Rankic and D. W. C. MacMillan, Chem. Rev., 2013, 113, 5322-5363.

10 (a) R. A. Aycock, H. Wang and N. T. Jui, Chem. Sci., 2017, 8, 3121-3125; (b) A. J. Boyington, M. L. Y. Riu and N. T. Jui, J. Am. Chem. Soc., 2017, 139, 6582-6585.

11 For other examples of photoredox catalysis in aryl radical chemistry, see: (a) A. Arora and J. D. Weaver, Acc. Chem. Res., 2016, 49, 2273-2283; (b) I. Ghosh, L. Marzo, A. Das, R. Shaikh and B. Konig, Acc. Chem. Res., 2016, 49, 15661577; (c) J. D. Nguyen, E. M. D'Amato, J. M. R. Narayanam and C. R. J. Stephenson, Nat. Chem., 2012, 4, 854-859; (d) E. H. Discekici, N. J. Treat, S. O. Poelma, K. M. Mattson, Z. M. Hudson, Y. Luo, C. J. Hawker and J. R. de Alaniz, Chem. Commun., 2015, 51, 11705-11708.

12 (a) A. G. Myers and J. L. Gleason, J. Org. Chem., 1996, 61, 813815; (b) D. Seebach and W. B. Schweizer, J. Am. Chem. Soc., 1983, 105, 5390-5398; (c) R. C. F. Jones, D. J. C. Berthelot and J. N. Iley, ARKIVOC, 2007, 73-84; (d) P. Kolar, A. Petric and M. Tisler, J. Heterocycl. Chem., 1997, 34, 1067.

13 (a) I. Rilatt, L. Caggiano and R. F. W. Jackson, Synlett, 2005, 18, 2701-2719; (b) K. M. M. Huihui, J. A. Caputo, Z. Melchor, A. M. Olivares, A. M. Spiewak, K. A. Johnson, T. A. Dibenedetto, S. Kim, L. K. G. Ackerman and D. J. Weix, J. Am. Chem. Soc., 2016, 138, 5016-5019; (c) X. Lu, J. Yi, Z.-Q. Zhang, J.-J. Dai, J.-H. Liu, B. Xiao, Y. Fu and L. Liu, Chemistry, 2014, 20, 15339-15343.

14 (a) H. J. Kreuzfeld, C. Dobler, U. Schmidt and H. W. Krause, Amino Acids, 1996, 269-282; (b) M. Adamczyk, S. R. Akireddy 
and R. E. Reddy, Org. Lett., 2001, 3, 3157-3159; (c) C. Dobler, H. J. Kreuzfeld, M. Michalik and H. W. Krause, Tetrahedron: Asymmetry, 1996, 7, 117-125.

15 J. Deska, in Radical-Mediated Synthesis of $\alpha$-Amino Acids and Peptides, in Amino Acids, Peptides and Proteins in Organic Chemistry: Building Blocks, Catalysis and Coupling Chemistry, 2010, vol. 3.

16 (a) T. H. Wright, B. J. Bower, J. M. Chalker, G. J. L. Bernardes, R. Wiewiora, W.-L. Ng, R. Raj, S. Faulkner, M. R. J. Vallee, A. Phanumartwiwath, O. D. Coleman, M.-L. Thezenas, M. Khan, S. R. G. Galan, L. Lercher, M. W. Schombs, S. Gerstberger, M. E. Palm-Espling, A. J. Baldwin, B. M. Kessler, T. D. W. Claridge, S. Mohammed and B. G. Davis, Science, 2016, 354, aag1465; (b) A. Yang, S. Ha, J. Ahn, R. Kim, S. Kim, Y. Lee, J. Kim, D. Söll, H.-Y. Lee and H.-S. Park, Science, 2016, 354, 623-626.

17 M. S. Lowry, J. I. Goldsmith, J. D. Slinker, R. Rohl, R. A. Pascal Jr, G. G. Milliaras and S. Bernhard, Chem. Mater., 2005, 17, 5712-5719.

18 (a) C. P. Andrieux, C. Blocman, J. M. Dumas-Bouchiat and J. M. Saveant, J. Am. Chem. Soc., 1979, 101, 3431-3441; (b)
R. J. Enemærke, T. B. Christensen, H. Jensen and K. Daasbjerg, J. Chem. Soc., Perkin Trans. 2, 2001, 1620-1630.

19 A. L. J. Beckwith and L. Chai, J. Chem. Soc., Chem. Commun., 1990, 1087-1088.

20 S. Karady, S. Amato and M. Weinstock, Tetrahedron Lett., 1984, 25, 4337-4340.

21 D. Seebach and F. Antoine, Helv. Chim. Acta, 1985, 68, 12431250.

22 (a) K. Okada, K. Okamoto, N. Morita, K. Okubo and M. Oda, J. Am. Chem. Soc., 1991, 24, 9401-9402; (b) G. L. Lackner, K. W. Quasdorf, G. Pratsch and L. E. Overman, J. Org. Chem., 2015, 80, 6025-6036; (c) T. Qin, J. Cornella, C. Li, L. R. Malins, J. T. Edwards, S. Kawamura, B. D. Maxwell, M. D. Eastgate and P. S. Baran, Science, 2016, 352, 801805; (d) K. M. M. Huihui, J. A. Caputo, Z. Melchor, A. M. Olivares, A. M. Spiewak, K. A. Johnson, T. A. DiBenedetto, S. Kim, L. K. G. Ackerman and D. J. Weix, J. Am. Chem. Soc., 2016, 138, 5016-5019.

23 (a) J. Panigrahi, M. Eggen, J.-H. Maeng, Q. Shen and D. Berkowtiz, Chem. Biol., 2009, 16, 928-936; (b) R. Dave, B. Badet and P. Meffre, Amino Acids, 2003, 24, 245-261. 